\title{
Exercise tolerance improves after pulmonary rehabilitation in pulmonary hypertension patients
}

\author{
Arunabh Talwar ${ }^{1,2, *}$, Sonu Sahni, ${ }^{1,2,3}$, Sameer Verma ${ }^{1,2}$, Sara Z. Khan ${ }^{4}$, Sean Dhar ${ }^{1}$, Nina Kohn ${ }^{5}$ \\ ${ }^{1}$ Northwell Health, Department of Pulmonary, Critical Care and Sleep Medicine, New Hyde Park, NY, USA \\ ${ }^{2}$ The Feinstein Institute for Medical Research, Center for Heart and Lung Research, Manhasset, NY, USA \\ ${ }^{3}$ Department of Primary Care, Touro College of Osteopathic Medicine, New York, NY, USA \\ ${ }^{4}$ American University of Antigua, Osbourn, Antigua and Barbuda \\ ${ }^{5}$ Department of Biostatistics, The Feinstein Institute for Medical Research, Manhasset, NY, USA
}

Pulmonary rehabilitation (PR) is part of the recommended management plan of pulmonary hypertension (PHTN) and is important to better quality of life and exercise tolerance. This study aimed at determining effectiveness of PR on exercise capacity. Retrospective chart analysis was conducted on patients referred to our PHTN clinic for PR. Patients who had PHTN diagnosed on right heart catheterization (defined by mean pulmonary artery pressure $>25 \mathrm{mmHg}$ ) and completed a standardized 12-week PR program were considered for the study. Patients' baseline exercise tolerance was recorded as speed attainable on a treadmill and duration of exercise in minutes. Demographics, age, sex, and oxygen use were obtained from chart review. Eighteen PHTN patients (5 male, 13 female; mean age $67.7 \pm 11.6$ years) were considered for the study (six World Health Organization [WHO] group 1 pulmonary arterial hypertension [33.33\%], eight WHO group III PHTH [44.44\%], two WHO group IV and two WHO V PHTN [11.11\%]). Treadmill speed improved following rehabilitation (1.3 mph [interquartile range $\{\mid \mathrm{QR}\}, 1.0-1.8 \mathrm{mph}$ ] to $2.2 \mathrm{mph}$ [IOR, 1.3-2.8 mph]; $P<0.0001$, Wilcoxon signed rank test). Median exercise time improved (27 min (IQR, 22-30 min) to $30 \mathrm{~min}$ (IOR, 24-30 min); not significant. Improvement was defined only as an increase in speed or duration, or both. Sixteem of 18 participants improved (88.9\% [95\% exact binomial confidence interval, 65.3\%-98.6\%). Patients with PHTN benefit from a structured PR program to improve their exercise capacity and should be enrolled in PR programs as part of their management.

Keywords: Pulmonary hypertension, Pulmonary rehabilitation, Pulmonary arterial hypertension, Treadmill speed, Exercise tolerance

\section{INTRODUCTION}

Pulmonary hypertension (PHTN) is a rare and devastating disease characterized by progressive increases in pulmonary arterial pressure and pulmonary vascular resistance which eventually leads to right ventricular failure and death (Badesch et al., 2009; Farber and Loscalzo, 2004). It may due to various etiologies such as left heart disease, parenchymal lung disease, chronic thromboembolic disease, hematologic disorders or it may be idiopathic in nature though the clinical picture of these patients is similar (Simonneau et al., 2013). Patients with and advanced lung disease such as PHTN face symptomatology consistent with oxygen deprivation, including dyspnea, fatigue and exercise intolerance. Pulmonary rehabilitation (PR) in patients with PHTN patients is in fact important in the management as it improves outcomes (Sahni et al., 2015). This study is aimed at determining the effectiveness of structured PR program on exercise capacity in a population of PHTN patients.

\section{MATERIALS AND METHODS}

\section{Study population and design}

We conducted a retrospective review of data collected on $18 \mathrm{pa}-$ tients with diagnosis of PHTN who participated in the Northwell
${ }^{*}$ Corresponding author: Arunabh Talwar (D) http://orcid.org/0000-0003-2290-7562 Northwell Health, Department of Pulmonary, Critical Care and Sleep Medicine, 410 Lakeville Rd. Suite 107 New Hyde Park, NY 11040, USA

Tel: +1-516-465-5400, Fax: +1-516-465-5454, E-mail: arunabhtalwar1@gmail.com Received: December 6, 2016 / Accepted: March 28, 2017
This is an Open Access article distributed under the terms of the Creative Commons Attribution Non-Commercial License (http://creativecommons.org/licenses/by-nc/4.0/) which permits unrestricted non-commercial use, distribution, and reproduction in any medium, provided the original work is properly cited. 
Table 1. Patient demographics $(\mathrm{n}=18)$

\begin{tabular}{lc}
\hline Demographic & Value \\
\hline Age (yr) & $67.7 \pm 11.6$ \\
Sex & \\
Male & $5(27.8)$ \\
Female & $13(72.2)$ \\
WHO groups & \\
I & $6(33.3)$ \\
II & $0(0)$ \\
III & $8(44.4)$ \\
IV & $2(11.1)$ \\
V & $2(11.1)$ \\
WHO functional class & \\
I & $1(5.6)$ \\
II & $7(38.9)$ \\
III & $9(50.0)$ \\
IV & $1(5.6)$ \\
\hline
\end{tabular}

Values are presented as mean \pm standard deviation or number (\%). WHO, World Health Organization.

Health PR program. For the purposes of the study PHTN was defined in accordance to the most updated guidelines of the American College of Chest Physicians and the European Respiratory Society (Galie et al., 2015). PHTN was defined hemodynamically as a mean resting pulmonary artery pressure greater than or equal $25 \mathrm{mmHg}$ and pulmonary arterial hypertension (PAH) was a pulmonary artery wedge pressure less than or equal to 15 $\mathrm{mmHg}$ on right heart catheterization (Galie et al., 2015). As the World Health Organization (WHO) has proposed a classification system for PHTN based on common clinical features and etiology which has been outlined in Table 1 (Simonneau et al., 2013). Our patients were categorized into WHO groups of PHTN based on underlying etiology of PHTN and completed a standardized 12week PR program to be considered for the study.

\section{Pulmonary rehabilitation}

All patients considered for the study completed our PR program. The PR program at our center has been certified by the American Association of Cardiovascular and Pulmonary Rehabilitation and is designed towards adult patients with chronic lung disease or patients preparing/recovering from lung surgery. The program consists of an exercise and education component with three sessions weekly over a period of 12 -week period. Following the completion of the 12-week program, maintenance sessions are also available for patients to participate.

The rehab facility at our site is equipped with exercise equip- ment such as treadmill, upper/lower body recumbent stepper (NuStep LLC, Ann Arbor, MI, USA), arm ergometers and free weights. In addition, safety equipments available include: electrocardiogram monitoring, pulse oximetry, blood pressure monitoring and supplemental oxygen. The education component consists of biweekly educational lecture series that comprise of breathing techniques along with stress and relaxation exercises. As part of our PR program all patients are asked to fill out quality of life, fatigue and sleep questionnaires before and after completion of the program.

At the time of the enrollment in PR, all patients were clinically stable, and all were receiving optimal medical therapy. Patients' baseline exercise tolerance was recorded as speed attainable on a treadmill in miles per hour (mph) and duration of exercise in minutes (min). Demographics, age, sex, New York Heart Association functional class and oxygen use were obtained from chart review. Data were analyzed using SAS ver. 9.3 (SAS Institute Inc., Cary, NC, USA). The change in each component of the treadmill exercise (speed, grade, duration), was examined using the Wilcoxon signed rank test. Improvement was defined as an increase in speed or duration (or both), with no decrease in either component). The percent of subjects who improved based on this definition was then calculated, along with the associated exact binomial 95\% confidence interval. Northwell Health System Institutional Review Board approval was obtained for this study (approval number: 14-574).

\section{RESULTS}

Eighteen patients with PHTN met the criteria for the study. There were a total of 5 male and 13 female patients with a mean age $67.7 \pm 11.6$ years. Of these patients there were six $(33.33 \%$ who were considered WHO group $1 \mathrm{PAH}$ ), eight WHO group III PHTN (44.44\%), two WHO group IV, and two WHO V PHTN (11.11\%). Demographics have been outlined in Table 1. Of these patients, 14 (82.4\%) were on supplemental oxygen. It was found that as a whole across all WHO groups of PHTN, treadmill speed improved following rehab $(P<0.0001$, Wilcoxon signed rank test). Median treadmill speed prior to rehab was 1.3 $\mathrm{mph}$ (interquartile range [IQR], 1.0-1.8 mph) and $2.2 \mathrm{mph}$ (IQR, 1.3-2.8 mph) following rehab Fig. 1.

Prior to rehab, median exercise time was $27 \mathrm{~min}$ (IQR, 22-30 $\mathrm{min}$ ), after rehab, median exercise time was $30 \mathrm{~min}$ (IQR, 24-30 $\mathrm{min})$. The total exercise time also improved though not found to be statistically significant. Sixteen of the 18 participants improved (88.9\%; 95\% exact binomial confidence interval, 65.3\%-98.6\%). 


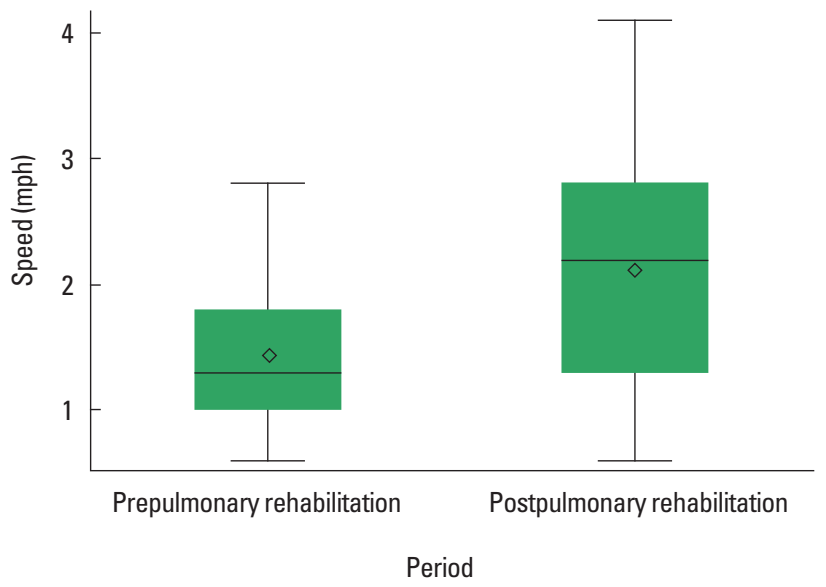

Fig. 1. Pre- and postpulmonary rehabilitation treadmill speed.

\section{DISCUSSION}

PHTN treatment is centered on improved cardiopulmonary hemodynamics resulting in increased exercise tolerance as generally measured by the 6-min walk test. This emerging data has been seen specifically in the WHO group I PAH (Babu et al., 2016; Chan et al., 2013). Our study shows exercise tolerance improvements in terms of speed in mph and increased duration of exercise across multiple etiologies of PHTN after a course of structured PR. The results of this study also demonstrate that despite diagnostic etiology of PHTN and disease severity structured PR increases exercise tolerance.

The American Thoracic Society and the European Respiratory Society have defined pulmonary rehabilitation as an "evidence based, multidisciplinary and comprehensive intervention for patient with chronic respiratory diseases who are symptomatic and often have decreased daily life activities" (Nici et al., 2006). The principal purpose of PR programs is to improve function, disease related symptoms, optimize functional capacity and an overall improvement in quality of life.

The use PR as an adjuvant to pharmacotherapy is well established (Nici et al., 2006). PR has become a staple of therapy in advanced lung disease including chronic obstructive pulmonary disease (Casaburi et al., 2005), idiopathic pulmonary fibrosis (Raghu et al., 2011) and PHTN (Mereles et al., 2006) amongst others. Early thought process of exercise in PHTN was that it may be harmful, expedite the disease process and may even cause sudden death. However, evidenced based medicine has proven the opposite to be true (Sahni et al., 2015). The underlying mechanism of PR resulting in an increased exercise tolerance remains conjectur- al. Disease mechanism in PHTN heavily involves endothelin-1 (ET-1), the human body's most potent vasoconstrictor. Studies have shown that chronic exercise causes an increase in the production of nitric oxide, a potent vasodilator and a decrease in the production of ET-1 which in turn may net a vasodilatory effect thereby decreasing pulmonary vascular resistances, increasing cardiac output and increasing exercise tolerance (Maeda et al., 2001). It is also important to note that the overall increase of speed in our pulmonary rehab patients points to an increase in exercise tolerance and endurance. Patients who were unable to increase their overall speed showed an increase in the duration of time there were able to exercise also pointing to an increased in endurance. A study by Otsuki et al. (2006) showed that ET-1 concentrations were lower in individuals who participated in strength or endurance training as compared to sedentary controls. As the knowledge and beneficial evidence of PR steadily increases the use in PHTN patients should continue to become part of standard of care.

In conclusion our study was able to show that patients with all types of PHTN and varying WHO functional class show improvement as measured by speed and time from a structured PR program. All PHTN patients should be enrolled in PR programs as part of their management in adjuvant to their pharmacotherapy and regardless of their WHO functional class.

\section{CONFLICT OF INTEREST}

No potential conflict of interest relevant to this article was reported.

\section{REFERENCES}

Babu AS, Padmakumar R, Maiya AG, Mohapatra AK, Kamath RL. Effects of exercise training on exercise capacity in pulmonary arterial hypertension: a systematic review of clinical trials. Heart Lung Circ 2016;25: 333-341.

Badesch DB, Champion HC, Sanchez MA, Hoeper MM, Loyd JE, Manes A, McGoon M, Naeije R, Olschewski H, Oudiz RJ, Torbicki A. Diagnosis and assessment of pulmonary arterial hypertension. J Am Coll Cardiol 2009;54(1 Suppl):S55-66.

Casaburi R, Kukafka D, Cooper CB, Witek TJ Jr, Kesten S. Improvement in exercise tolerance with the combination of tiotropium and pulmonary rehabilitation in patients with COPD. Chest 2005;127:809-817.

Chan L, Chin LM, Kennedy M, Woolstenhulme JG, Nathan SD, Weinstein AA, Connors G, Weir NA, Drinkard B, Lamberti J, Keyser RE. Benefits of intensive treadmill exercise training on cardiorespiratory 
function and quality of life in patients with pulmonary hypertension. Chest 2013;143:333-343.

Farber HW, Loscalzo J. Pulmonary arterial hypertension. N Engl J Med 2004;351:1655-1665.

Galiè N, Humbert M, Vachiery JL, Gibbs S, Lang I, Torbicki A, Simonneau G, Peacock A, Vonk Noordegraaf A, Beghetti M, Ghofrani A, Gomez Sanchez MA, Hansmann G, Klepetko W, Lancellotti P, Matucci M, McDonagh T, Pierard LA, Trindade PT, Zompatori M, Hoeper M. 2015 ESC/ERS Guidelines for the diagnosis and treatment of pulmonary hypertension: The Joint Task Force for the Diagnosis and Treatment of Pulmonary Hypertension of the European Society of Cardiology (ESC) and the European Respiratory Society (ERS): Endorsed by: Association for European Paediatric and Congenital Cardiology (AEPC), International Society for Heart and Lung Transplantation (ISHLT). Eur Respir J 2015;46:903-975.

Maeda S, Miyauchi T, Kakiyama T, Sugawara J, Iemitsu M, Irukayama-Tomobe Y, Murakami H, Kumagai Y, Kuno S, Matsuda M. Effects of exercise training of 8 weeks and detraining on plasma levels of endothelium-derived factors, endothelin-1 and nitric oxide, in healthy young humans. Life Sci 2001;69:1005-1016.

Mereles D, Ehlken N, Kreuscher S, Ghofrani S, Hoeper MM, Halank M, Meyer FJ, Karger G, Buss J, Juenger J, Holzapfel N, Opitz C, Winkler J, Herth FF, Wilkens H, Katus HA, Olschewski H, Grünig E. Exercise and respiratory training improve exercise capacity and quality of life in patients with severe chronic pulmonary hypertension. Circulation 2006;114:1482-1489.

Nici L, Donner C, Wouters E, Zuwallack R, Ambrosino N, Bourbeau J,
Carone M, Celli B, Engelen M, Fahy B, Garvey C, Goldstein R, Gosselink R, Lareau S, MacIntyre N, Maltais F, Morgan M, O'Donnell D, Prefault C, Reardon J, Rochester C, Schols A, Singh S, Troosters T; ATS/ERS Pulmonary Rehabilitation Writing Committee. American Thoracic Society/European Respiratory Society statement on pulmonary rehabilitation. Am J Respir Crit Care Med 2006;173:1390-1413.

Otsuki T, Maeda S, Iemitsu M, Saito Y, Tanimura Y, Ajisaka R, Goto K, Miyauchi T. Effects of athletic strength and endurance exercise training in young humans on plasma endothelin-1 concentration and arterial distensibility. Exp Biol Med (Maywood) 2006;231:789-793.

Raghu G, Collard HR, Egan JJ, Martinez FJ, Behr J, Brown KK, Colby TV, Cordier JF, Flaherty KR, Lasky JA, Lynch DA, Ryu JH, Swigris JJ, Wells AU, Ancochea J, Bouros D, Carvalho C, Costabel U, Ebina M, Hansell DM, Johkoh T, Kim DS, King TE Jr, Kondoh Y, Myers J, Müller NL, Nicholson AG, Richeldi L, Selman M, Dudden RF, Griss BS, Protzko SL, Schünemann HJ; ATS/ERS/JRS/ALAT Committee on Idiopathic Pulmonary Fibrosis. An official ATS/ERS/JRS/ALAT statement: idiopathic pulmonary fibrosis: evidence-based guidelines for diagnosis and management. Am J Respir Crit Care Med 2011;183:788-824.

Sahni S, Capozzi B, Iftikhar A, Sgouras V, Ojrzanowski M, Talwar A. Pulmonary rehabilitation and exercise in pulmonary arterial hypertension: An underutilized intervention. J Exerc Rehabil 2015;11:74-79.

Simonneau G, Gatzoulis MA, Adatia I, Celermajer D, Denton C, Ghofrani A, Gomez Sanchez MA, Krishna Kumar R, Landzberg M, Machado RF, Olschewski H, Robbins IM, Souza R. Updated clinical classification of pulmonary hypertension. J Am Coll Cardiol 2013;62(25 Suppl):D34-41. 